\title{
“DOCTORS JUST DON'T CARE ABOUT PEOPLE!" HOW MEDICAL SPECIALISTS ARE DEPICTED IN A VACCINE-CRITICAL ESTONIAN FACEBOOK GROUP
}

\author{
Marko Uibu \\ Lecturer, Institute of Social Studies \\ University of Tartu, Estonia \\ marko.uibu@ut.ee
}

\begin{abstract}
Vaccine hesitancy as a great health risk is related to trust in healthcare providers' recommendations and provider-parent interaction. The negative image of doctors and their motives may hinder open communication and trustful relationship. As the role of the internet as a source for health information and emotional support has become significant, social media discussions about health and medicine provide valuable opportunities to observe the formation of critical attitudes towards doctors and medicine. This article examines representations of medical specialists in an Estonian vaccine-critical public Facebook group. On the forum, doctors are depicted as dumb and blind believers who operate in a wrong paradigm and are not able to see the full and accurate picture of "real health". According to the group rhetoric, doctors' willingness to help parents and children is limited as they depend on a broader exploitive medical system or Big Pharma. As medical specialists are not trustworthy and do not take any responsibility, parents feel that they must closely control all the actions. The group members believe that it is better not tell the truth to doctors and, if necessary, to threaten them with law enforcement. Many of the forum posts are very emotional, illustrating the heavy burden parents perceive in taking vaccine-related decisions. The ridiculing of medical specialists has an empowering effect on patients to feel more in control. Forum posts emphasize common belonging and shared concerns. Therefore, social media is not only a stage for vaccine information but an active factor contributing to the circulation of meanings and enabling emotional support and community formation.
\end{abstract}

Keywords: anti-vaccine culture, childhood vaccination, doctor-patient relationship, health communication, internet forum, representation of doctors, vaccine hesitancy

As vaccine hesitancy has become one of the greatest health risks according to the World Health Organization (WHO 2019), the multifaceted phenomenon 
of hesitant or refusing parents has been heavily studied (Dubé et al. 2018; Reich 2018 [2016]; Majid \& Ahmad 2020). Despite numerous calls for potential interventions to increase vaccination rates (Smith 2017; Salmon et al. 2015), no strong evidence has been found to support any intervention that addresses vaccine hesitancy and refusal (Sadaf et al. 2013; Dubé et al. 2018). However, health professionals' important role in addressing parents' concerns and maintaining public trust in vaccination has been emphasized (Leask et al. 2012; Connors \& Slotwinski \& Hodges 2017). Trust in healthcare providers' recommendations and personalized provider-parent interaction are the main reasons why vaccinehesitant parents might still decide to vaccinate their children (Yaqub et al. 2014; Connors \& Slotwinski \& Hodges 2017). The negatively biased images of doctors and their motives could hinder open communication and trustful relationship. As the role of the internet as a health information source has become significant, the present study examines representations of medical specialists in the stories that are posted in a vaccine-critical Facebook group.

In its broadest sense, vaccine hesitancy is a symptom of the erosion of trust in medicine and pharmaceutics. There are several social and cultural processes behind the hesitancy, such as a general distrust in big corporations and a pursuit of the natural and ecological (Attwell et al. 2017) as well as salutogenic lifestyle and parenting (Ward et al. 2017). Parents have become critical consumers of health services and products (Yaqub et al. 2014). Foremost, vaccine hesitancy is a problem of wealthy developed societies and privileged parents who have time and resources to execute "individualist parenting" (Reich 2018 [2016]). Also, the efficiency of vaccines is eroding the perception of their necessity: as vaccineavoidable diseases have become rare, people do not perceive them as a threat.

In the review of 34 qualitative studies, Majid \& Ahmad (2020: 1762) identified seven main factors influencing the decision not to vaccinate children: previous experiences; "natural" and "organic" lifestyle; perceptions of other parents' behaviour and attitudes; interactions with health care providers; information sources; distrust in health system players; and mandatory vaccine policies. Hesitancy and opposition to vaccines are supported by topical information channels on the internet (Tangherlini et al. 2016). Internet forum discussion topics cover most of the key factors for vaccination decisions (Majid \& Ahmad 2020).

Having doctors as the main information source decreases hesitancy as compared to other sources (Yaqub et al. 2014). Increasingly, sharing information on online health platforms is taking over the role of expert knowledge by providing more opinions of "lay experts" (Prior 2003), as well as networks of other common people sharing their experiences (Griffiths et al. 2012; Bakke 2018). Internet forums have contributed to the growing diversity of "healthcare knowledge cultures" (Keeling \& Khan \& Newholm 2013). The increasing diversity in 
the context of health has been depicted as postmodern fragmentation and the emergence of diverse microcultures (Thompson \& Troester 2002). Alternative health-focused channels hold and support specific norms and regimes of normality and increase distrust in the medical system. Online health communities have proven to be the sources of knowledge and even more - of emotional and affective support (Oerle \& Mahr \& Lievens 2016). Participation creates social capital (Stewart Loane \& Webster 2017); specific (speech) communities are formed that are characterized by common understandings, norms, and communication styles (Uibu 2012). Internet discussions on health allow people to take the expert role and address topics that could otherwise be ostracized (Kõiva 2009).

Many parents, especially the more vaccine-critical ones, claim to have the internet as an important source of information (Kender 2018). Parents' affective connection based on a similar position and easily relatable personal stories on internet sites may contribute to the adoption of certain beliefs and value positions (Tangherlini et al. 2016). The decision to vaccinate a child or refuse vaccines is highly relational: the proportion of non-vaccination attitudes in the members of the parents' network predicted their non-vaccination decision better than any other trait, even their own explicit attitudes towards vaccination (Brunson 2013). The deeper rationale for vaccine hesitancy in high-income countries is quite homogenous (Dubé et al. 2018). However, the medical system and cultural norms for health differ and create culture-specific patterns.

The present study focuses on Estonia - a country with a state-funded medical system and newly emerging forms of medical pluralism and anti-medicine discourses (Uibu 2020; Koppel \& Uibu 2020). Already historically, compared to the consumerist healthcare models of the West, the Soviet-style "motherly" care involved high professional medical authority, mandatory regular medical check-ups, and administrative power given to doctors (Haug 1976), which caused feelings of paternalistic inequality and low personal agency of patients. Even the contemporary post-Soviet medical systems are still more normative than in the West; there is a much weaker sense of autonomy and the mentality of doctors' "independent profession" (Riska \& Novelskaite 2011). "Paternalistic" and "consumerist" approaches in doctor-patient relationship have fundamental differences that can easily lead to conflicts (Beisecker \& Beisecker 1993).

The polarization in the understandings about health and legitimate sources of health-related knowledge poses challenges for interactions between doctors and patients. Estonian healthcare professionals have been hostile towards alternative medicine and health approaches (Tikk 2005; Uibu 2020). Doctors who encounter anti-vaccine parents more often tend to become more intolerant and less willing to discuss their concerns (Leib \& Liberatos \& Edwards 2011). There 
is an intense discussion held by Estonian medical specialists about "brainwashed" patients believing in the fraudulent CAM (Uibu \& Koppel forthcoming). On the other hand, the emerging discourse by CAM proponents depicts "narrow-minded" physicians and medical science being corrupted by the Big Pharma (ibid.). These differences create communication barriers: for example, when patients perceive the hostility of the doctor towards CAM, they avoid telling about their CAM experiences and plans (Lubi \& Vihalemm \& Taba 2016).

Estonian vaccination policies are liberal: vaccines are not mandatory but strongly recommended. ${ }^{1}$ Still, some ten years ago, the percentage of vaccinated children was well over the herd immunity requirement of 95 percent but has dropped since then. All the estimations based on different methodologies and data sets demonstrate a steady decline. Compared to 2009, 3 percent more parents refused to vaccinate in 2019 (Health Board 2020). According to doctors' official reports, all the vaccines were administered to less than half of the 8 -year-olds and no vaccines to 6.5 percent. Parents' refusals were marked in 13.6 percent of all the children (Tamm et al. 2020).

Several anti-vaccine groups and people have emerged in Estonia in recent years; for example, NGO Estonian Parents of Vaccine Injured Children. In addition to several translated and published books, the internet has probably become the most important source of vaccine-related information. Among numerous vaccine-related posts in the most popular Estonian forum Perekool (Family school), vaccine-critical posts were proportionally strongly over-represented (Noorem 2015). Curiously, the forum Perekool belongs to the Estonian Midwives Association and should therefore be supposedly not biased towards anti-vaccine position. The content analysis of the forum posts suggests that the posters have settled attitudes towards vaccination and seek reassurance for their current beliefs and behaviour on the forum (Noorem 2015). It has been suggested that anonymous personal stories shared on the anti-vaccine Facebook forum may deepen the readers' distrust and fear of vaccines and healthcare workers (Mägi 2020).

The present study focuses on one lively community on the Estonian-speaking internet - a Facebook group dedicated to sharing information and discussing the adverse effects of medicine and vaccines. Considering the important role of medical experts in the vaccination process raises two main questions: (1) How do the group members depict medical specialists and medical system? and (2) What kind of suggestions and specific tools are shared for communicating with medical specialists? 


\section{METHODS AND THE SITE OF RESEARCH}

The study is based on online ethnography and the analysis of the posts in the Estonian Facebook group Ravimite ja vaktsiinide kõrvaltoimed (Side-effects of medicines and vaccines). ${ }^{2}$ I chose this specific group due to several reasons: it is fully public and has very active and numerous membership (ca 13,000 people by the end of 2020). The study could be placed most broadly under the discipline of health and medical anthropology which emphasizes "fundamental importance of culture and social relationships in health and illness" (Singer et al. 2019 [2007]: 8). Taking the online group as the main site of research, I have followed the principles of passive online/digital ethnography (Pink et al. 2016) and "netnography" (Kozinets 2019). However, the analysis of online material is strongly supported by my deeper familiarity with alternative health subcultures as my ethnographic fieldwork has included participation in offline events and interviews with people with alternative and anti-vaccine attitudes.

I have been a member of the "side effects" group almost since its foundation in 2017. My interest in the group grew out of my long-term research on Estonian spiritual and alternative "milieu" and a specific interest in health-related issues. During my fieldwork since 2011, I have been a member of social media groups for new spirituality, alternative medicine, and conspiracy theories, and have participated in thematic "offline" events (see a more detailed overview in Uibu 2016 and 2020). Internet has become an excellent fieldwork location for contemporary folklore to detect stories and narratives shared in various communities (Kõiva \& Vesik 2009). The intensity of online health-related communication has led many ethnographers to observe the 'alternative lifestyle' online communities to analyse, for example, online narratives and behavioural intentions in health-related misinformation (Lavorgna \& Myles 2021). Ethnographies of social media have become a developing field (Wilson 2019).

My low-intensity online ethnography in the "side effects" group involved reading and making notes during a longer period of two and a half years. In those observations I noticed regular occurrences of stories about personal encounters with doctors as well as specific instructions for how to handle these situations. Therefore, I examined these topics more systematically, with a focus on the depictions of doctors. The present study is based on a corpus of topical texts, consisting of 28 longer threads with comments (altogether 955 posts, most of them short). ${ }^{3}$ Ten of these threads started with personal stories about vaccination experiences and side-effects, three were posted by the administrator as anonymous narratives. Using qualitative thematic analysis, I coded the texts and identified different elements characteristic of the depictions of medical specialists. 
The "side effects" group is explicitly critical of vaccines and the medical system. Even the description of the group emphasizes its dedication to antivaccine information. The need for that is explained by the aggressive pro-vaccine campaigns and multitude of information available "from this side": as information in favour of medicines and vaccines can be found in official channels, this information is not disseminated in this group. The group does not aim to provide a platform for balanced information and critical arguments for different positions. It is presented and administered to be a haven for vaccine-critical opinions and experiences as the group's rules emphasize that they keep the focus on understanding and helping, not confrontation. Based on the argumentation analysis of the "side effects" group posts, it was concluded that highly emotional stories contained several argumentation and logical errors that were overlooked in the comments (Mägi 2020).

The important function of the group is to get and give advice and specific suggestions (including with diagnoses or health problems), but the group's description explicitly rejects any liabilities regarding the information shared:

The Facebook group does not offer professional advice. Its aim is to exchange information and broaden horizons. Each member of the group is responsible for what he or she says but is not responsible for anyone treating his or her story as something other than the free expression of a common citizen. The promoters or administrators of this group are not responsible for any ideas or advice posted here. ${ }^{4}$

Although the group is positioned as a parents' forum, some active members and authors are professionally related to alternative medicine. The group had more than 13,000 members by the end of 2020 . Although both men and women post on the forum, women tend to submit more stories about encounters with doctors and more emotional-personal information while men rather share conspiracytype information.

The "side effects" group offers a great opportunity to see how vaccine-related discussions take place on a public platform. With an aim to attract attention and operate as an information source and promotion channel not only for the members but also on a broader scale, this group is maximally public so that anyone can see who is in the group and what they post, including non-registered users.

The research on (childhood) vaccines and the use of online discussion material is ethically sensitive. Despite the fact that all forum texts are public, I have followed several ethical considerations. I do not refer to any names. The posts are in Estonian, therefore, already the translation process eliminates the chance to search direct quotes on the forum. In addition, for more sensitive examples I have used quotes from anonymous stories. Therefore, translated quotes from 
the forum do not lead to actual postings and even if it were somehow trackable, the anonymous stories could not be related to any specific person. Furthermore, I have deliberately focused on the rhetoric and meanings and do not go deeper into specific personal examples that could cause harm or reveal the identities of the writers. As my observations remained passive, I did not ask for informed consent forms from the group members as I felt that it would have been practically infeasible for 955 posts as well as disconcerting and too intrusive. Similar considerations have been followed in current research standards (Lavorgna \& Myles 2021).

As the observation period included the beginning of the COVID pandemic, the dynamics and the proportion of the users' posts changed considerably due to the increasing amount of COVID-related material. The virus information comes mainly from international conspiracy-theory and "alternative" groups and websites. Due to these posts, the dynamic of the group has changed, containing more information from international sources, conspiracy-related memes, and clips. Also, the dangers of COVID tests (and the mandatory nature of those) and vaccines are heavily and very emotionally discussed. However, stories about encounters with doctors and specific questions still remain on the forum despite its shift towards COVID-related material and conspiracy theories.

\section{RESULTS}

Doctors and the medical system are crucial participants in the vaccination process. In the "side effects" group, people commonly share personal stories about encounters with doctors and ask for advice about how to handle these situations. In addition to certain ways of depicting doctors, the posts feature some characteristic elements of style and rhetoric. For example, there is a significant number of markers of common belonging: emphasis on "us", and "we as young mothers" clearly unite the group. The style of the posts is very emotional, especially in the stories that are personal and painful. Generally, the names of the medical specialists are not mentioned in the stories despite the severe accusations and detailed descriptions. There are very few direct confrontations. The doctor is rather presented as an impersonal caricature, referred to as a "generic" and faceless category. There are also several posts that are rhetorically addressed to pro-vaccine doctors with pleas and warnings. As the group is homogenous and probably not involving any doctors who could be convinced, it seems to be a rhetorical tactic to add severity to the claims.

There are also certain repeated elements in how doctors are depicted. In the first subchapter I will point out some main characteristics of medical experts presented in the stories and comments. 


\section{Portrayal of medical specialists}

\section{Doctors as dumb and blind believers}

Several funny and mocking stories or dialogues depict doctors as having very limited knowledge and a blind belief in vaccines. One viral transcript of a dialogue presents a mother asking critical questions about tetanus vaccine from a doctor who wants to administer it to her child who has a fresh wound. Due to the mother's examination, the cornered doctor is not able to provide coherent responses - or finally any responses at all - so the punchline is that, according to the doctor's logic, the vaccine would start to protect the child a week after the child's potential death by tetanus. The clever and courageous mother concludes: "Scares me that I have more information than a physician. It should scare you, too." (T10)

This story and many similar others emphasize the limitedness of knowledge the doctors have and their inability to understand the basic principles. The comments section includes many exclamations, such as "How silly can he be?!" (T10-C6). Indeed, some of the doctors are depicted as so incompetent that it raises some doubts about the accuracy of the stories. Retrospective personal narratives that are presented with significant bravado could, indeed, be altered versions that adjust the actual course of action. The story "as it could have happened" helps to give power back to the mother and lets her feel that she has cleverly and elegantly stood up for herself and the child.

\section{Doctors operating in a wrong paradigm are not able to see the full} and accurate picture

Similar to the dumb doctor's narrative, it is common to explain doctors' limited understandings not only with their intellectual incapacities but with the fact that they are wearing blinders to the narrow paradigm of Western medicine. As a common critique by alternative health practitioners, this discourse depicts vaccines as useless because real health comes from healthy lifestyle and "natural healing".

The trouble is that, unfortunately (at least it seems that way), no school of medicine teaches the integrity of the body... they do not teach the causes and why diseases arise at all, nor do they teach how to heal naturally. (T1-C48)

It is believed that faith in Western medicine hinders achieving better health but may also be outright dangerous. Vaccines, for example, are believed to interrupt 
the "normal" functioning of a body and add poisonous elements. Furthermore, more critical posts are accusing scientific medicine of being the very reason for so many diseases and patients.

...we have too many patients, which is the direct result of the medical industry. Just as the military industry ignites wars to sell weapons that only boost wars, so does the medical industry try to do everything to have more diseases, to sell more drugs that cause even more diseases, and so on.

Dear doctors, take a couple of weeks of unpaid leave, analyse your work and the results that you have achieved. Think about how many people you have healed - completely healed - with your common methods "taught" by pharmaceutical companies. Use your logical thinking and conclude that it is time to quit the role in dealership and resume the former dream that you had before entering university - TO BE THE ONE WHO HELPS PEOPLE. (T16)

\section{Emphasis on an exploitive system}

The previous quote strongly emphasizes the role of "industry", "pharmaceutical companies", and "university". The doctor is not seen as a caring expert but part of a big manipulative system that functions in its own interests. This argument has many variants, from purely organizational aspects (like a special credit system) to the deeper conspiracies of the Big Pharma.

\section{Vaccination bonuses as a motivation for a doctor}

Several posts give "insights" into the system, explaining doctors' behaviour and requests based on some implicit logic behind the actions. In one of the stories, a parent described how the GP put pressure on her to vaccinate or to sign official refusal letters (T23). The discussion quickly delved into the explanation that she was most probably "collecting points and rewards based on that [number of vaccinated children]", but also conspirational hints to pressure "from above" that the doctors have:

It is very suspicious that your GP woke now; in general, they do not bother anymore after the age of 3 because for their scoring system these children are out of the suitable age range and GPs cannot collect rewards anymore. Only when the child goes to school, then again [they are] back in the scoring system but then you must visit the doctor to get the bill of 
health anyway. The question arises as to why, from somewhere above right now, the family doctor was pressurized and who made them collect the signatures....??? (T23-C5)

This hidden agenda "from above" could be more present in Estonia because of the historical experience with the hierarchical and opaque Soviet system, but it is also a common element of conspiracy logic that assumes powerful hidden influences and actors.

\section{Doctor as an entrepreneur}

As in the Estonian system GPs have to operate and budget their practice, this is another factor casting doubt on their suggestions and decisions. Vaccines are seen as a steady flow of income, memes with slogans like "a healed patient is a lost patient" are shared. One commenter directly explains it: "After all, family doctors are entrepreneurs; the purpose of entrepreneurs is to make a profit, not to treat the sick" (T21-C2).

\section{Doctors are the puppets for the Big Pharma}

The depiction of the pharmaceutical industry as hugely influential and immoral is a core element of conspiracy theories. On the forum, the manipulations by the Big Pharma are a common knowledge which initiates emotional pleas to doctors like "Please co-operate with parents, not with Pharma!" (T16-C13). As the trope of linking doctors to the Big Pharma is very international, there are many clever memes shared, including pictures of doctors whose white robes are covered with the logos of pharmaceutical companies like sportsmen demonstrating their sponsors (Fig. 1).

Figure 1. A meme from the "side effects" Facebook group.

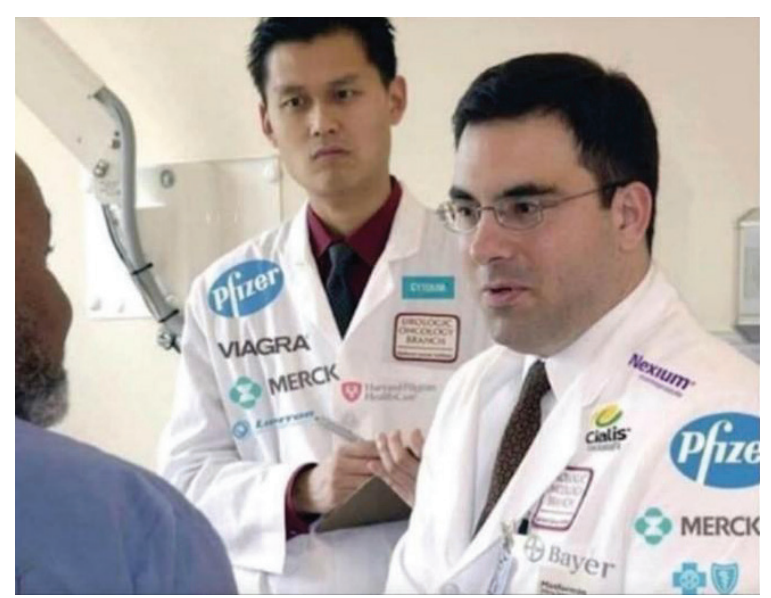




\section{Path dependency}

Some seemingly more emphatic posts try to understand the logic behind doctors' behaviour. After a story about vaccination resulting in a severe kidney failure, in which the author expressed puzzlement about how these grave mistakes could continue and be kept secret, a group member explains the logic:

It's very simple. If you're a family doctor who has given this injection [that allegedly caused the illness as a side effect] ... what do you do then? If you have something functioning in your brain, you will search Google (for vaccine associated nephropathy) and you will find that already 20 years ago some doctors wrote articles on the subject to look for a link between the vaccine and the nephrotic syndrome and other kidney damages. And then what do you do as a family doctor - do you look this parent in the eye and say that sorry, we weren't told about this at UT [University of Tartu where doctors are educated]? That they still tell students only that there's redness at the injection point - and fever and anaphylactic shock? No, you tell the parent that you don't know where it came from. Because by no means are you going to report it as a vaccine damage if none of the Estonian doctors up to the State Agency of Medicines have heard anything about this result [vaccine-caused disease] ... you will only be making a fool of yourself. And so it goes. And that's why there are so few of these reports and evidence; everything has been done to keep it that way. (T9-C12)

This explanation well illustrates the construction of a "system" and the logic that individual doctors might be unable and unwilling to stand up to. These are explained as broader norms and path dependencies that keep doctors doing such a harmful thing as vaccinations. As another person explains:

...doctors just do their job like other people. It is about a more general social system, one part of which is the medical system with pharmacy .... For the most part, people sincerely believe in and serve the whole system that they have created. Doctors just don't care about people. They only need to complete their plan. (T9-C38)

According to the posts, seeing through those alleged factors that influence doctors' behaviour is disillusioning and frustrating but also empowering. Although doctors are sometimes depicted as shrewd, their agendas and choices are generally presented as simple and predictable. Phrases like "As I expected..." are common to depict doctors' reactions or attitudes. This fulfils several functions: offers a somehow superior position and an insightful point of view but also constructs a certain norm - it is so common and predictable that doctors' behaviour follows certain patterns which are not in the interests of a patient. 


\section{Doctors as treacherous agents}

However, several narratives contain suspicions about doctors' motives - and some of them have proven to be correct. According to the stories, even if doctors seemingly act as if taking care of the patient, they rather execute their hidden agenda of administering vaccines. Thus, doctors could be treacherous, giving just an impression and acting as a helpful expert.

In one highly emotional anonymous story, the mother accuses vaccinations of killing her new-born baby. She argues that vaccine shots were given behind her back; describes several occasions when she tried to be more involved in and oversee the process but doctors "gently" pushed her away. For example, already before giving birth she tried to talk about vaccines and her planned refusal with the doctor: "Before I gave birth, the doctor said that she had read the statement of refusal, but I should focus on my delivery" (T2).

Shortly after the birth the child was taken from the mother for measurements:

I argued that maybe she [the nurse] could do it later so that I could come myself. I was told that under no circumstances ... that I had to rest from childbirth. Against my will, I handed over my child for a while, but I felt that it was suspicious. (T2)

According to her story, the child was later returned with several strange symptoms (inactivity, torpidity). The child's health deteriorated quickly and soon she died. The mother points out the potential causes of death and accuses vaccines, which is very much agreed to in the comments. The implicit element in the story is the explanation of how she tried her best to take care of and protect the child, but assumingly the caring doctors and nurses managed to trick her. The story also illustrates the paternalistic approach that she perceived in communicating with doctors and nurses.

Similar to this story, it seems that the driving force for many posts is the unanswered doubts about vaccination effects and the perceived guilt over not doing enough to protect the child when health problems occur. The active users on the forum present the dangerousness of vaccines as granted. Blaming vaccines is something that the parent of a sick child would prefer to believe as it gives some certainty in the emotionally extremely difficult situation. If the explanation of the negative effect of a vaccine settles, it is probably exceedingly difficult to turn it around. 


\section{Doctors do not take any responsibility}

The question of responsibility appears regularly on the forum and points out the heavy burden that parents perceive. Even a small likelihood of a potential vaccine damage is a huge risk as the parent is the one who has allowed the vaccination to take place. However, the decision not to vaccinate also involves risks - if an unvaccinated child gets a disease, it is the parents' fault. One mother shares her suspicions about vaccines but then ponders about the potential risks of leaving the child without the protection of vaccines: "Isn't it too much of a responsibility that if something should happen, the doctors will say it's your own fault not having [the child] vaccinated, so you're responsible now?" (T23) This post gets multiple responses, such as "you are always the only one who is responsible" (T23-C2). It is emphasized that the burden of responsibility is much greater in the case of side effects of vaccines because nobody in the medical system would even admit that the health problem is the result of a vaccination.

The following quote from a mother who believes that vaccines have caused a severe illness to her child sums up several of the different motives pointed out above:

I would never have thought that the doctors we trust as young mothers and hand over our healthy children to them could finally turn our lives and children's health upside down.

I'm so exhausted by all this, I just live one day at a time.

If only I had known before that we could do so much for the health of our children by researching and deciding ourselves.

We will not give up; we will continue to fight for the health of our children. Now that you've read the stories of other mothers, please think before you trust that the doctor still knows exactly what they're doing. After all, they do not take responsibility, they do not have to live with your sick child. (T17-C66)

This warning and the war-cry-like post illustrate well the pressure parents experience. In a very individualist paradigm about guarding their children, there is a strong emphasis on the common situation the parents have found themselves in. The group offers an opportunity to share this considerable emotional and liability burden. 


\section{Specific suggestions for communication with doctors}

The perception of a doctor as an adversary means that the encounters with them are perceived as challenges and need special preparations. On the forum, some specific advice is given about how to behave and what to tell the doctor. As a general suggestion, one mother emphasizes the importance of preparations before a visit: "Try to be tough and firm. Prepare yourself well before going to the doctor $\bigcirc$ " (T17-C10). Obviously, the critical pre-set disposition influences the interaction as well as the interpretation of a doctor's behaviour and messages. Therefore, the forum discussions create expectations and a specific lens through which to look at the encounters with a doctor.

\section{Suggestions to control/monitor all the actions}

Several posts and suggestions reflect the perceived necessity of constant control. In one thread, a pregnant woman shares her fears and asks for advice.

I have a bit of a phobia about the fact that when I go [to give birth], maybe after the birth the baby will be taken away for a while and the shot will be secretly given... should someone be kept next to the baby all the time? (T8)

This fear illustrates severe distrust in doctors and nurses. In the same thread, another user suggests specific forms of refusal as well as the need to "keep an eye on things".

I would recommend preparing two documents [vaccine refusals] and having both signed by the doctor, stating that they have read and accepted $i t$. Then one will stay with you and the other will be in hospital. In any case, ask somebody to keep an eye on things. I'm going to give birth soon as well. The same fears. 궁 (T8-C5)

Characteristically, the writer emphasizes her own very similar position as a pregnant mum, which creates a sense of a shared situation and community. The forum also gives specific advice about how to submit forms of refusal: specific formats and file templates are shared.

\section{Suggestions of what to tell the doctor to avoid vaccines}

It is suggested that telling a doctor that the child is coughing or has other signs of illnesses could avoid getting vaccinations. Some members also give recommendations of how to give false impressions concerned with other issues. 
If you want a sick note, say to the doctor that you have back pain ... it can't be checked but will get you the document (my story is illegal... but it works). (T13-C31)

Tricking doctors into believing certain things is considered to be a good solution.

\section{Threatening with law}

Although avoiding direct confrontations seems to be the preferred scenario, there are also several suggestions of how to impose your position and rights. For example, it is pointed out that by referring to law it is possible to defy the doctor's authority:

Even if there are no plans to go to court, threatening to do so is the only way to really demand that they follow the law. Otherwise, they will do whatever they want and no one will even look into what is or is not written in the laws. (T28)

Similarly, very confident posts illustrate that parents perceive that they have all the legal rights. According to this view, doctors can dominate in the medical expert sphere but have no power outside of it.

\section{Suggestions about doctors who tolerate vaccine refusal}

Internet forums and parents' groups are an important source for finding doctors who tolerate vaccine-hesitant parents or even more, are themselves critical of vaccines. The conversations illustrate well the normative nature of the Estonian medical sphere. For example, the names of the doctors are not shared publicly. When asked for recommendations about doctors who are not hostile towards non-vaccination decisions (this is a recurrent topic on the forum), people are asked to contact in a private message. One happy parent describes her encounter with a new doctor:

I transferred to her list knowing that she herself was against vaccines and a proponent of naturopathy. Namely, I knew two anti-vax friends on her list already before, and this doctor had dropped a few subtle hints to them in secrecy. So, towards the end of the visit today, the doctor asked me how we were going to do about vaccines. Knowing her position, I replied with an extremely satisfied face that neither of my children had received any vaccines and I would continue to do so. The doctor then looked me deep in the eye, and a smile appeared on her face, which is not something 
that anti-vaccine parents would get often as a response to this answer. A wide, joyful, sincere smile, full of absolute understanding and the joy of recognition! It could be read from her face that she would have wanted to say something as well, but the family nurse, who obviously is in favour of vaccines, was there at the same time, with her back to the doctor at that moment. I smiled at her. It was a complete understanding without words. After that, the already pleasant doctor became even more pleasant, and her respect for us was palpable. And of course mutual! Her attitude created a very pleasant mood for me for the whole day, and I am sincerely glad that there are doctors in our medical system who are actually seers! (:) $\bigcirc(\mathrm{T} 14)$

Although it seems that there are not many doctors like the one described above, this post still got some responses with similarly good experiences. Mainly there are numerous requests to share the doctors' names: "Could you write the names of these doctors in a private message, please? :)" (T14-C3)

This secrecy creates a sense of a community of illumined rebels who understand and share the "actual knowledge" and are against the repressive norms and "the system". It may also resonate with Estonian recent past as during the Soviet rule some topics were a taboo and hidden. Obviously, the repressed knowledge constituted the truth in comparison to the flawed state propaganda. Paradoxically, the privacy settings of the group are as public as possible so everybody's responses could be found even without logging in to Facebook. Therefore, the secrecy and closedness is an illusion created in the group.

\section{DISCUSSION, CONCLUSIONS}

Social media discussions about health and medicine provide valuable opportunities to observe the formation of critical attitudes towards doctors and medicine. Social media is not only a stage but an active factor contributing to the circulation of stories and meanings by enabling specific formats for discussions and community formation.

Anti-vaccine proponents point out many elements that are part of the common critique of Western medicine, such as the medical approach being very narrow in addressing human health (Lázár \& Johannessen 2006) and simultaneously colonizing too many spheres of life due to medicalization (Conrad 1992). Also, pharmaceutical companies undoubtedly influence the medical system. Total distrust in medicine expressed on the "side effects" forum illustrates the difficult challenge of keeping a balance between acknowledging problems in medicine and having enough confidence not to avoid medical expertise and 
help. Obviously, the overly critical opinions on the forum do not necessarily mean that users would keep these convictions in other social situations or refuse medical services. Online discussions are a specific format and attitudes expressed there do not have to correlate with actual behaviour. It has also been pointed out that even strong opposition to vaccines does not evoke opposition to medicine or trust in doctors in general (Attwell et al. 2017). However, if a parent has already chosen to join a group like "side effects", it may easily broaden their scope of distrust as the torrent of "alternative" information and the accusations addressed to doctors are so overwhelming. "Preparations for meeting a doctor", based on forum suggestions, could influence the interaction with medical specialists. Also, it could considerably complicate the procedures when parents do not agree to leave their child in the care of medical specialists or are very suspicious about any suggestions the doctors give.

As the "side effects" group involves people with diverse attitudes, the discussions are not homogenous, and some dissenting views can be detected. Some users bring out their experience and impressions, such as "my GP really cares about my child" and similar dissenting opinions. Most of the posts and active participants still keep an overly critical tonality; besides, the rules of the forum also emphasize that it is not allowed to share pro-vaccine information. The accusations could, therefore, become too radical and offensive to relate to moderately hesitant and critical parents - driven by group dynamics, radicalizing statements could alienate more moderate readers.

On the other hand, the emotional tonality of the comments serves an important function. Stories shared by parents are usually very personal and often traumatic. Told from a perspective of an average parent, the emotional relatability supports the positive reception of stories and messages. The emotionally very difficult content blocks dissenting views efficiently: you cannot easily tell a mourning mum that there are gaps and illogicalities in her story. Critical posts in these situations may be dismissed as rude and offensive. The community bolsters affective participation - parents often describe decisions that they have already taken or plan to take. In these cases, it is not about asking information for deciding but for getting confirmations. The emotional support is evident -it is reassuring to receive hundreds of supportive and emotional messages. It has been argued that the success of similar online communities derives from each other's mutual support, reassurance, and a sense of agency given, which helps to gain control over their lives. It is not only about persuasion but restorative narratives that enable the members "to find a renewed sense of the self, of morality and of purpose" (Lavorgna \& Myles 2021: 15).

The motifs from the forum illustrate the pressure parents perceive, which expresses in the hesitancy about vaccines and any decisions related to that. 
Hesitancy as a concern or doubt about the value or safety of vaccination is an increasingly extensive phenomenon (Yaqub et al. 2014). It is much broader than the direct refusal of vaccines or active anti-vaccine movements. Increasing hesitancy has become a natural part of contemporary parenting (Reich 2018 [2016]). The pressure to perform as a good parent is probably one of the reasons why parents come to the forum to get confirmations about their choices and not to feel alone with the decision to refuse vaccines. The received feedback and support easily normalize vaccine refusals.

The forum gives an opportunity to talk like an expert - give advice, express opinions. The storytelling on the forum could also be a re-performative attempt to alter the actual interaction with doctors. Some dialogues that depict a doctor or a nurse as highly incompetent are so unrealistic that it is very unlikely that these occasions have actually happened. Rather, they resemble folktales or urban legends which act as restorative narratives. The aspect of not mentioning any names and the fact that people share stories anonymously encourages this kind of "empowering" alterations.

In the pro-medicine and science discourse, ridiculing of non-scientific and alternative methods is a common tactic (Uibu \& Koppel forthcoming). In the Facebook group of vaccine-critical people, ridiculing is turned around - the doctors with their "fancy" training are depicted as limited, errant, and bound to the repressive system. Doctors in the stories are commonly reduced to caricature-like simplistic figures - mostly silly and predictable, working for the "system". A deeper contact with a doctor could help to contradict those sketchy descriptions. The doctor's empathic approach to vaccine-hesitant parents would probably surprise parents who have read several discussions on the forum - although it could be interpreted also as shrewdness and hidden agenda. Another suggestion for medical specialists would be to openly discuss and admit some inherent flaws and problems in the medical system. It could help to disrupt the perception of polarized stances and of the doctor/nurse as being on the other side of the frontline.

Due to historical-cultural reasons and the public health insurance system, Estonian medical culture is more hierarchical and paternalistic than private medicine in the USA; for example, it keeps the provider-client relationships and a flexible vaccination approach (Reich 2018 [2016]). Therefore, depicting doctors as narrow-minded or even ridiculous helps to "empower" Estonian patients and break up the perceived hierarchies. Several parents seem to be very selfconfident even in the posts that are grammatically heavily misspelled and incompetent content-wise. However, vaccine hesitancy is generally more common to privileged parents with a better education and financial situation - the opposition towards vaccines is clearly an elitist pursuit (ibid.). Characteristically, 
vaccine-critical parents think much about health issues and might have concerns and knowledge that a doctor is, indeed, not able to respond to. Very healthconscious parents are not satisfied with standard procedures and require extra attention and tailor-made plans for their child. Also, the influence of more holistic and alternative health discourses, which depict Western medicine as severely limited, is clearly visible.

This study has raised several concerns about the risks related to the "side effects" and other similar social media groups. Indeed, it would be best if people did not feel the need to search for information and try to get confirmations from (anti-vaccine) Facebook groups. However, lively discussions and the great number of personal stories in this group indicate that these forms of communication are important and fitting for people. Therefore, it could be beneficial to provide accurate health information and discuss popular health concerns in formats that allow a closer contact, such as personal stories, discussions, and suggestions based on those. Forums and collections of stories including the ones with (seemingly or actual) adverse effects in a more balanced medium would deprive people with a clear anti-vaccination agenda of the possibility to shape attitudes. It would also be important to acknowledge the pressure that parents perceive. It is not only information that people need but also emotional support and the opportunity to share their doubts. Doctors and medical specialists as genuinely interested listeners may be a model that these moderated environments could offer.

The development of the anti-vaccine movement and attitudes towards the medical system and specialists in different countries would need a comparative study. A broader social context for vaccination decisions and the healthcare system in general influence information sharing and relations with doctors. For example, Estonian schools do not require vaccination and there are basically no limitations on travelling or public services for not vaccinating children. Therefore, the interactions with doctors become the major pressure points in Estonia as doctors have the most direct task to persuade parents. This is probably one of the reasons why medical specialists have become the main adversaries on the forum as other, rather liberal systems, give parents more freedom and do not direct them to vaccinate.

It is visible that anti-vaccine culture has become highly (and increasingly) global - the "side effects" group provides many links, audio-visual material, and translated texts, some without any indication that it does not originate from Estonia. With COVID fears and considerations, the group dynamics has changed considerably, and conspiracy theories have taken the main stage people share material in different languages, and the information flow has intensified. It is still unclear what kind of impact the pandemic and the COVID 
vaccinations exert on the anti-vaccine subculture and especially on hesitant people. As vaccination will most probably be voluntary, the low uptake could constitute a new and urgent problem. However, the pressure parents perceive because of childhood vaccine decisions remains one of the core issues driving the vaccine debates. Undoubtedly, internet platforms have an important role in this matter.

\section{NOTES}

1 Vaccines are given by the same doctor/nurse who does the mandatory health check-ups for children. Estonian GPs are called "family doctors" and nurses "family nurses" as they are supposed to have a good connection to the whole family. However, too long lists of patients mean that the strong doctor-patient connection is not that common, especially in the cities.

2 See https://www.facebook.com/groups/282626385574048, last accessed on 9 February 2021.

${ }^{3}$ In the results section, the number of a thread for a quote is marked with $\mathrm{T}$ and if the quoted text is from a comment to an original post, the position of the comment in the thread is marked with $\mathrm{C}$. Although some active users posted regularly, all the quotes in the article are from different users (unintentionally).

${ }^{4}$ See https://www.facebook.com/groups/282626385574048, last accessed on 9 February 2021.

5 The text illustrates that people do not share only their personal stories: the dialogue cited is translated into Estonian from English and was distributed broadly on Englishlanguage sites already in 2017 but reached Estonia in 2020. However, in the story there is no indication that it is not a personal story or has not happened in Estonia.

\section{REFERENCES}

Attwell, Katie \& Leask, Julie \& Meyer, Samantha B. \& Rokkas, Philippa \& Ward, Paul 2017. Vaccine Rejecting Parents' Engagement with Expert Systems That Inform Vaccination Programs. Journal of Bioethical Inquiry, Vol. 14, No. 1, pp. 65-76. http://dx.doi.org/10.1007/s11673-016-9756-7.

Bakke, Abigail 2018. Credibility Strategies of Popular Health Websites: A Rhetorical Analysis of Parkinson's Information Pages. In: K. P. Hunt (ed.) Understanding the Role of Trust and Credibility in Science Communication. https://doi.org/10.31274/ sciencecommunication-181114-4.

Beisecker, Analee E. \& Beisecker, Thomas D. 1993. Using Metaphors to Characterize Doctor--Patient Relationships: Paternalism Versus Consumerism. Health Communication, Vol. 5, No. 1, pp. 41-58. http://dx.doi.org/10.1207/s15327027hc0501_3. 
Brunson, Emily K. 2013. The Impact of Social Networks on Parents Vaccination Decisions. Pediatrics, Vol. 131, No. 5, pp. e1397-e1404. http://dx.doi.org/10.1542/ peds.2012-2452.

Connors, John T. \& Slotwinski, Kate L. \& Hodges, Eric A. 2017. Provider-parent Communication When Discussing Vaccines: A Systematic Review. Journal of Pediatric Nursing, Vol. 33, pp. 10-15. https://doi.org/10.1016/j.pedn.2016.11.002.

Conrad, Peter 1992. Medicalization and Social Control. Annual Review of Sociology, Vol. 18, No. 1, pp. 209-232. http://dx.doi.org/10.1146/annurev.so.18.080192.001233.

Dubé, Eve \& Gagnon, Dominique \& MacDonald, Noni \& Bocquier, Aurélie \& PerettiWatel, Patrick \& Verger, Pierre 2018. Underlying Factors Impacting Vaccine Hesitancy in High Income Countries: A Review of Qualitative Studies. Expert Review of Vaccines, Vol. 17, No. 11, pp. 989-1004. https://doi.org/10.1080/1476 0584.2018.1541406.

Griffiths, Frances \& Cave, Jonathan \& Boardman, Felicity \& Ren, Justin \& Pawlikowska, Teresa \& Ball, Robin \& Cohen, Alan 2012. Social Networks: The Future for Health Care Delivery. Social Science \& Medicine, Vol. 75, No. 12, pp. 2233-2241. http:// dx.doi.org/10.1016/j.socscimed.2012.08.023.

Haug, Marie R. 1976. The Erosion of Professional Authority: A Cross-Cultural Inquiry in the Case of the Physician. The Milbank Memorial Fund Quarterly. Health and Society, Vol. 54, No. 1, pp. 83-106.

Health Board 2020 = Nakkushaiguste vastu vaktsineerimise ülevaated kvartalite ja aastate lõikes. [Vaccination Reviews of Infectious Diseases by Quarters and Years.] Available at https://www.vaktsineeri.ee/et/statistika, last accessed on 1 March 2021.

Keeling, Debbie \& Khan, Amna \& Newholm, Terry 2013. Internet Forums and Negotiation of Healthcare Knowledge Cultures. Journal of Services Marketing, Vol. 27, No. 1, pp. 59-75. http://dx.doi.org/10.1108/08876041311296383.

Kender, Elisa 2018. Eesti lapsevanemate vaktsineerimiskäitumine ning arusaamad ja uskumused seosed vaktsineerimisega. [Estonian Parents' Vaccination Behaviour and Vaccination-related Beliefs.] Diploma thesis. Tartu Tervishoiu Kõrgkool.

Kõiva, Mare 2009. On-Line Medicine. Communication and Narratives. In: Mare Kõiva (ed.) Media \& Folklore. Contemporary Folklore IV. Tartu: ELM Scholarly Press, pp. 162-183. Available at http://www.folklore.ee/rl/pubte/ee/cf/cf4/, last accessed on 10 February 2021.

Kõiva, Mare \& Vesik, Liisa 2009. Contemporary Folklore, Internet and Communities at the Beginning of the 21st Century. In: Mare Kõiva (ed.) Media and Folklore. Contemporary Folklore IV. Tartu: ELM Scholarly Press, pp. 97-117. Available at http://www.folklore.ee/rl/pubte/ee/cf/cf4/, last accessed on 10 February 2021.

Koppel, Katre \& Uibu, Marko 2020. 'Not Even All Physicians Know Chinese Medicine!': Analysing the Legitimation Strategies of Chinese Medicine in the Estonian Media. Journal of Ethnology and Folkloristics, Vol. 14, No. 1, pp. 1-24. Available at https://www.jef.ee/index.php/journal/issue/view/26, last accessed on 10 February 2021.

Kozinets, Robert V. 2019. Netnography: The Essential Guide to Qualitative Social Media Research. Los Angeles \& London \& New Delhi \& Singapore \& Washington DC \& Melbourne: SAGE. 
Lavorgna, Anita \& Myles, Heather 2021. Science Denial and Medical Misinformation in Pandemic Times: A Psycho-Criminological Analysis. European Journal of Criminology, pp. 1-21. https://doi.org/10.1177\%2F1477370820988832.

Lázár, Imre \& Johannessen, Helle 2006. Epilogue: Multiple Medical Realities: Reflections from Medical Anthropology. In: Helle Johannessen \& Imre Lázár (eds.) Multiple Medical Realities: Patients and Healers in Biomedical, Alternative and Traditional Medicine. New York \& Oxford: Berghahn Books, pp. 183-198.

Leask, Julie \& Kinnersley, Paul \& Jackson, Cath \& Cheater, Francine \& Bedford, Helen \& Rowles, Greg 2012. Communicating with Parents about Vaccination: A Framework for Health Professionals. BMC Pediatrics, Vol. 12, No. 1. http:// dx.doi.org/10.1186/1471-2431-12-154.

Leib, Susan \& Liberatos, Penny \& Edwards, Karen 2011. Pediatricians' Experience with and Response to Parental Vaccine Safety Concerns and Vaccine Refusals: A Survey of Connecticut Pediatricians. Public Health Reports, Vol. 126, 2nd suppl., pp. 13-23. http://dx.doi.org/10.1177/00333549111260S203.

Lubi, Kadi \& Vihalemm, Triin \& Taba, Pille 2016. Patients' Interpretation of CAMRelated Information: Manoeuvring Between Patient and Consumer Positionings. In: V. Marinescu \& B. Mitu (eds.) The Power of the Media in Health Communication. London \& New York: Routledge, pp. 73-90.

Mägi, Kadri-Ann 2020. Anonü̈̈msete kogemuslugude roll vaktsiinivastases kommunikatsioonis: Facebooki grupi "Ravimite ja vaktsiinide kõrvaltoimed" analü̈̈s. [The Role of Anonymous Experience Stories in Anti-vaccine Communication.] Unpublished master's thesis. University of Tartu. Available at https://dspace. ut.ee/bitstream/handle/10062/67860/magi_kadri_ma_2020.pdf, last accessed on 15 February 2021.

Majid, Umair \& Ahmad, Mobeen 2020. Vaccines in the 21st Century: Clarifying the Factors That Promote Vaccine Hesitancy, Delay, and Rejection. Health Science Inquiry, Vol. 11, No. 1, pp. 123-127. https://doi.org/10.29173/hsi285.

Noorem, Marilin 2015. Laste vaktsineerimisega seotud arutelud Perekooli foorumis. [Discussions on Children's Vaccination on Perekool Forum.] Unpublished bachelor's thesis. University of Tartu. Available at http://dspace.ut.ee/bitstream/handle/10062/46763/noorem_marilin_ba_2015.pdf, last accessed on 15 February 2021.

Pink, Sarah \& Horst, Heather \& Postill, John \& Hjorth, Larissa \& Lewis, Tania \& Tacchi, Jo 2016. Digital Ethnography: Principles and Practice. London \& Thousand Oaks \& New Delhi \& Singapore: SAGE.

Prior, Lindsay 2003. Belief, Knowledge and Expertise: The Emergence of the Lay Expert in Medical Sociology. Sociology of Health \& Illness, Vol. 25, No. 3, pp. 41-57. http://dx.doi.org/10.1111/1467-9566.00339.

Reich, Jennifer A. 2018 [2016]. Calling the Shots: Why Parents Reject Vaccines. New York: New York University Press.

Riska, Elianne \& Novelskaite, Aurelija 2011. Professionalism and Medical Work in a Post-Soviet Society: Between Four Logics. Anthropology of East Europe Review, Vol. 29, No. 1, pp. 82-93.

Sadaf, Alina \& Richards, Jennifer L. \& Glanz, Jason \& Salmon, Daniel A. \& Omer, Saad B. 2013. A Systematic Review of Interventions for Reducing Parental Vaccine Refusal and Vaccine Hesitancy. Vaccine, Vol. 31, No. 40, pp. 4293-4304. http:// dx.doi.org/10.1016/j.vaccine.2013.07.013. 
Salmon, Daniel A. \& Dudley, Matthew Z. \& Glanz, Jason M. \& Omer, Saad B. 2015. Vaccine Hesitancy: Causes, Consequences, and a Call to Action. Vaccine, Vol. 33, Suppl. 4, pp. D66-D71. DOI: 10.1016/j.vaccine.2015.09.035.

Singer, Merrill \& Baer, Hans \& Long, Debbi \& Pavlotski, Alex 2019 [2007]. Introducing Medical Anthropology: A Discipline in Action. Lanham \& Boulder \& New York \& London: Rowman \& Littlefield.

Smith, Tara C. 2017. Vaccine Rejection and Hesitancy: A Review and Call to Action. Open Forum Infectious Diseases, Vol. 4, No. 3. http://dx.doi.org/10.1093/ofid/ofx146.

Stewart Loane, Susan \& Webster, Cynthia M. 2017. Social Capital and Consumer Value Co-Created Within an Online Health Community. Journal of Nonprofit \& Public Sector Marketing, Vol. 29, No. 3, pp. 317-345. http://dx.doi.org/10.1080/104951 42.2017.1326359.

Tamm, Sirli \& Raie, Evelin \& Käär, Ruth \& Oja, Marek \& Reisberg, Sulev 2020. Eesti eelkooliealiste laste hõlmatus immuniseerimiskava vaktsiinidega 2010. aasta sünnikohordi põhjal Eesti Haigekassa raviarvete alusel. [Coverage of Immunization Schedule Vaccinations among Estonian Preschool Children on the Basis of Estonian Health Insurance Claims of the 2010 Birth Cohort.] Eesti Arst: Eesti Arstide Liidu ajakiri, Vol. 99, No. 1, pp. 6-15. Available at https://ojs.utlib. ee/index.php/EA/article/view/16359/11295, last accessed on 15 February 2021.

Tangherlini, Timothy R. \& Roychowdhury, Vwani \& Glenn, Beth \& Crespi, Catherine M. \& Bandari, Roja \& Wadia, Akshay \& Falahi, Misagh \& Ebrahimzadeh, Ehsan \& Bastani, Roshan 2016. "Mommy Blogs" and the Vaccination Exemption Narrative: Results from a Machine-Learning Approach for Story Aggregation on Parenting Social Media Sites. JMIR Public Health and Surveillance, Vol. 2, No. 2, e166. https://doi.org/10.2196/publichealth.6586.

Thompson, Craig J. \& Troester, Maura 2002. Consumer Value Systems in the Age of Postmodern Fragmentation: The Case of the Natural Health Microculture. Journal of Consumer Research, Vol. 28, No. 4, pp. 550-571. http://dx.doi.org/10.1086/338213. Tikk, Arvo 2005. Arstid ja alternatiivmeditsiin. [Doctors and Alternative Medicine.] Eesti Arst, Vol. 84, No. 4, pp. 294-296. https://doi.org/10.15157/ea.v0i0.9870.

Uibu, Marko 2012. Creating Meanings and Supportive Networks on the Spiritual Internet Forum "The Nest of Angels". Journal of Ethnology and Folkloristics, Vol. 6, No. 2, pp. 69-86. Available at https://www.jef.ee/index.php/journal/article/ view/124, last accessed on 15 February 2021.

Uibu, Marko 2016. Religiosity as Cultural Toolbox: A Study of Estonian New Spirituality. Diss. (PhD Thesis). Tartu: Tartu University Press. Available at https://dspace. ut.ee/handle/10062/54063, last accessed on 15 February 2021.

Uibu, Marko 2020. The Emergence of New Medical Pluralism: The Case Study of Estonian Medical Doctor and Spiritual Teacher Luule Viilma. Anthropology and Medicine. https://doi.org/10.1080/13648470.2020.1785843.

Uibu, Marko \& Koppel, Katre. forthcoming. Beyond Medical Pluralism: Communicative Positioning of Biomedicine and CAM in Estonia. European Journal of Health Communication.

Van Oerle, Sarah \& Mahr, Dominik \& Lievens, Annouk 2016. Coordinating Online Health Communities for Cognitive and Affective Value Creation. Journal of Service Management, Vol. 27, No. 4, pp. 481-506. https://doi.org/10.1108/JOSM09-2015-0264. 
Ward, Paul R. \& Attwell, Katie \& Meyer, Samantha B. \& Rokkas, Philippa \& Leask, Julie 2017. Understanding the Perceived Logic of Care by Vaccine-Hesitant and Vaccine-Refusing Parents: A Qualitative Study in Australia. PLoS One, Vol. 12, No. 10, e0185955. https://doi.org/10.1371/journal.pone.0185955.

WHO 2019 = Ten Threats to Global Health in 2019. Available at https://www.who. int/news-room/spotlight/ten-threats-to-global-health-in-2019, last accessed on 15 February 2021.

Wilson, Richard Ashby 2019. The Digital Ethnography of Law: Studying Online Hate Speech Online and Offline. Journal of Legal Anthropology, Vol. 3, No. 1, pp. 1-20. http://dx.doi.org/10.2139/ssrn.3465225.

Yaqub, Ohid \& Castle-Clarke, Sophie \& Sevdalis, Nick \& Chataway, Johanna 2014. Attitudes to Vaccination: A Critical Review. Social Science \& Medicine, Vol. 112, pp. 1-11. http://dx.doi.org/10.1016/j.socscimed.2014.04.018.

Marko Uibu is a lecturer of communication studies at the Institute of Social Studies, University of Tartu, Estonia. His current academic interests are related to diverse aspects of social change and plurality: from religious and health perspectives to the possibilities of (co-)creating social change.

marko.uibu@ut.ee 